ORIGINAL ARTICLE

\title{
Does Day Length Affect Cognitive Performance in Memory Clinic Patients?
}

\author{
Catherine Lacny, Andrew Kirk, Debra G. Morgan, Chandima Karunanayake
}

\begin{abstract}
Objective: To determine whether day length affects cognitive performance in rural and remote memory clinic patients. Methods: A rural and remote memory clinic in Saskatoon, Saskatchewan provided an opportunity to examine how cognitive performance on the Mini-Mental State Exam (MMSE) is influenced by day length. Saskatchewan is an ideal location to test this association as day length varies greatly both seasonally and geographically. Following an initial assessment by the Rural and Remote Memory Clinic (RRMC) team in Saskatoon, patient follow-up appointments were performed either in-person or via telehealth videoconference. At each follow-up appointment the clinic neurologist administered the MMSE. The relationship between day length and MMSE scores at the sixweek follow-up appointment was analyzed in 154 patients. The mean daily temperature was controlled for in the analysis. Bivariate correlate and linear regression analyses were conducted. Results: There was no significant association between MMSE scores and either minutes of day length or mean daily temperature. Conclusion: Day length does not appear to have significant effect on cognitive performance of rural and remote memory clinic patients.
\end{abstract}

\begin{abstract}
RÉSUMÉ: La longueur du jour influence-t-elle la performance cognitive chez les patients fréquentant une clinique de la mémoire? Objectif : Le but de l'étude était de déterminer si la longueur du jour influence la performance cognitive chez des patients vivant en milieu rural ou éloigné. Méthode : Nous avons profité du contexte d'une clinique de la mémoire située à Saskatoon en Saskatchewan pour examiner si la longueur du jour influence la performance cognitive au Mini-Mental State Examination (MMSE). La Saskatchewan est un lieu idéal pour évaluer cette association étant donné que la longueur du jour varie énormément selon les saisons et la géographie. Les patients ont subi une évaluation initiale à Saskatoon par l'équipe d'une Clinique de la mémoire en milieu rural et éloigné. Le suivi était fait en personne ou par vidéoconférence en télésanté. Le neurologue de la clinique les évaluait au moyen du MMSE à chaque rendez-vous de suivi. Nous avons analysé la relation entre la longueur du jour et les scores au MMSE à l'examen de suivi 6 semaines après l'évaluation initiale chez 154 patients. Les données ont été soumises à des analyses de corrélation et de régression linéaire bivariées, tenant compte de la température moyenne quotidienne. Résultats : Nous n'avons pas observé d'association significative entre les scores au MMSE et la longueur du jour en minutes ou la température quotidienne moyenne. Conclusion : La longueur du jour ne semble par avoir un effet significatif sur la performance cognitive des patients d'une clinique de la mémoire située en milieu rural ou éloigné.
\end{abstract}

Can. J. Neurol. Sci. 2011; 38: 461-464

Light is an important environmental cue influencing circadian physiology. Early studies on light focused on intensity, generating hypotheses on the contribution of light exposure to human physiology that were based on bright light exposure. Experimental treatments, too, use light therapy in the form of bright light exposure. More recent studies suggest that natural light exposure also affects humans, as circadian systems have been shown to respond to low intensity natural lighting as well ${ }^{1}$. The pattern of depressive episodes and remission seen in patients with seasonal affective disorder suggests that environmental illumination is a factor in the etiology of the syndrome, and low sunlight exposure has been associated with significantly higher probability of cognitive impairment in depressed patients ${ }^{1-2}$. In addition, comparisons between winter and summertime performance on cognitive function tests have demonstrated summertime improvement in seasonal affective disorder patients who are in remission ${ }^{3}$.

From the Division of Neurology (AK), College of Medicine (CL), Canadian Centre for Health and Safety in Agriculture (DGM, CK), University of Saskatchewan, Saskatoon, Saskatchewan, Canada.

Received October 26, 2010. Final Revisions Submitted January 12, 2011 Correspondence to: Andrew Kirk, Division of Neurology, University of Saskatchewan, 103 Hospital Drive, Saskatoon, Saskatchewan, S7N 0W8, Canada. 
Sundowning denotes the clinical phenomenon of disruptive or agitated behaviour worsening in late afternoon or evening in dementia patients. Reported prevalence of sundowning in patients with dementia ranges from $2.4 \%$ to $66 \%$, with higher rates among patients with severe dementia 4 . While the mechanism is still unclear, it has been suggested that sundowning is the result of disturbed circadian rhythms caused by Alzheimer's disease and related dementias ${ }^{5}$. Currently, there is insufficient evidence to assess the effect of natural light exposure on dementia patients ${ }^{6}$. Because patients with severe dementia not only have higher rates of sundowning but are also more receptive to bright light therapy ${ }^{7}$, we suspect that the effects of day length may be more profound in participants with severe dementia and therefore lower Mini-Mental State Exam (MMSE) scores.

Saskatchewan is a rectangular province located in western Canada with its long axis oriented north-south between $49^{\circ}$ and $60^{\circ} \mathrm{N}$. There is large seasonal variation in day length, providing us with an opportunity to investigate the effect of day length on cognition in patients with dementia. This has not been assessed previously.

\section{Methods}

Data collection began in March 2004 at the Rural and Remote Memory Clinic (RRMC) in Saskatoon, Saskatchewan, Canada, where patients were referred by their family physician. Ethical approval was granted by the University of Saskatchewan Behavioural Research Ethics Board, and all patients and their families gave informed consent prior to participation. As the RRMC is directed to patients with early stage memory loss we assume the majority of patients are competent to provide consent, although this assumption cannot be confirmed until after the complete assessment has been conducted. For this reason, a family member was asked to witness the consent protocol for all patients. Patients were informed that family members co-signed the consent forms. Assessment began with a pre-clinic telehealth interview followed by a one-day in-person visit involving a neurologist, neuropsychologist, geriatrician and physiotherapist ${ }^{8}$. Patients were then seen in follow-up at 6weeks, 12-weeks, 6-months, 12-months and annually thereafter, or more often if clinically indicated. Follow-up appointments were generally conducted at the same time of day across all patients, between 13:00-15:00, in order to maintain constancy of the time of testing. Individual patients were randomly assigned to either in-person follow-up assessment in Saskatoon or telehealth assessment in their home community for their first follow-up visit. Visits thereafter alternated between in-person in Saskatoon or via telehealth. At each follow-up visit the same neurologist administered the MMSE to all patients. During telehealth assessments, the telehealth coordinator at the remote site provided the stimuli and material for copying, reading and writing. The MMSE was carried out according to the guidelines established by Folstein et $\mathrm{al}^{9}$. Our group has demonstrated in a prior publication that MMSE scores do not differ significantly between telehealth and in-person assessments; therefore telehealth provides an acceptable means of assessing mental status of patients in remote areas ${ }^{10}$. The MMSE scores from 154 patients at their 6-week follow-up appointment were used in this study (See Table 1). Our participant pool included the first 178
Table 1: Demographics and clinical characteristics of participants

\begin{tabular}{|c|c|}
\hline Total number of patients in study, $n$ & 154 \\
\hline Age at initial clinic day, years & $\begin{array}{l}73.9 \pm 9.8 \\
42 \text { to } 91\end{array}$ \\
\hline Gender, n (\%) & $\begin{array}{l}59(38.3 \%) \\
95(61.7 \%)\end{array}$ \\
\hline $\begin{array}{r}\text { Initial clinic day - } \\
\text { neurologist diagnosis, } n(\%) \\
\text { Alzheimer's disease (AD) } \\
\text { Mild cognitive impairment }{ }^{a} \text { impol dementia } \\
\text { Frontotemporal } \\
\text { Dementia with Lewy bodies } \\
\text { Vascular dementia } \\
\text { Mixed dementia - AD/vascular } \\
\text { Vascular cognitive impairment } \\
\text { Normal pressure hydrocephalus } \\
\text { Head injury } \\
\text { Sequelae of coronary artery bypass graft } \\
\text { Vitamin B12 deficiency } \\
\text { Parkinson's disease } \\
\text { Huntington's disease }\end{array}$ & $\begin{array}{l}86(55.8 \%) \\
23(14.9 \%) \\
12(7.7 \%) \\
10(6.5 \%) \\
7(4.5 \%) \\
5(3.9 \%) \\
4(2.6 \%) \\
2(1.2 \%) \\
1(0.6 \%) \\
1(0.6 \%) \\
1(0.6 \%) \\
1(0.6 \%) \\
1(0.6 \%)\end{array}$ \\
\hline $\begin{array}{r}\text { Mean } \pm \text { SD } \\
\text { Range }\end{array}$ & $\begin{array}{l}20.95 \pm 6.16 \\
0 \text { to } 29\end{array}$ \\
\hline
\end{tabular}

${ }^{\text {a }}$ Mild cognitive impairment (MCI) includes MCI, MCI due to other and MCI amnestic diagnoses; ${ }^{\mathrm{b}}$ Frontotemporal dementia (FD) includes FD frontal variant, FD semantic, and FD progressive non-fluent diagnoses.

patients seen by the memory clinic. Twenty-four patients were excluded due to a "normal" diagnosis following their assessment; therefore 154 patients were involved in the analysis.

The effect of day length on MMSE scores was examined. As temperature increases with longer day length, mean daily temperature was controlled for. Using National Research Council Canada's guidelines, day length was defined as the time from sunrise to sunset, referring to the appearance and disappearance, respectively, of the upper limb of the sun. Data was recorded in minutes and was acquired from the Canadian Weather Network's historical database. Mean temperature data was obtained from Environment Canada's National Climate Data and Information Archive and was recorded in degrees Celsius.

Eleven patients involved in the study lived in six communities that did not have a weather station on site, therefore the Weather Network and Environment Canada's databases did not have historical climate data for these locations. The Geographical Name Search Service offered by Natural Resources Canada provided the latitudinal and longitudinal coordinates for locations that did not have a weather station. These coordinates were then used in the National Research Council Canada's sunrise/sunset calculator. To obtain mean 
Table 2: Correlation and multiple linear regression analysis

\begin{tabular}{|c|c|c|c|c|}
\hline & \multicolumn{4}{|c|}{ MMSE Score } \\
\hline & \multicolumn{2}{|c|}{ All $(n=154)$} & \multicolumn{2}{|c|}{ MMSE score $\leq 22(n=72)$} \\
\hline & Estimate & $\mathrm{P}$ value $^{\mathrm{a}}$ & Estimate & $\mathrm{P}_{\text {value }}{ }^{\mathrm{a}}$ \\
\hline \multicolumn{5}{|l|}{$\begin{array}{l}\text { Correlation } \\
\text { Day length }\end{array}$} \\
\hline $\begin{array}{l}\text { Correlation coefficient } \\
\text { Mean temperature }\end{array}$ & -0.058 & 0.477 & 0.056 & 0.642 \\
\hline Correlation coefficient & -0.048 & 0.554 & -0.079 & 0.512 \\
\hline \multicolumn{5}{|l|}{$\begin{array}{l}\text { Multiple linear regression } \\
\text { Day length }\end{array}$} \\
\hline $\begin{array}{l}\text { Estimate } \pm S E \\
\text { Mean temperature }\end{array}$ & $-0.002 \pm 0.004$ & 0.693 & $0.008 \pm 0.005$ & 0.115 \\
\hline $\mathrm{R}^{2 \mathrm{~b}} \quad$ Estimate $\pm \mathrm{SE}$ & $\begin{array}{c}-0.004 \pm 0.066 \\
0.003\end{array}$ & 0.958 & $\begin{array}{c}-0.130 \pm 0.078 \\
0.042\end{array}$ & 0.101 \\
\hline
\end{tabular}

a $\mathrm{P}$ value from 2 -tailed $\mathrm{T}$ test; ${ }^{\mathrm{b}} \mathrm{R}^{2}$ is multiple coefficient of determination for regression.

temperature data in the event that there was no weather station on site, the mean temperature at the nearest location with a weather station was used. The nearest locations ranged from 5 $\mathrm{km}$ to $142 \mathrm{~km}$ away. None of the patients in this study were affected by daylight savings, which is observed in only one small area of Saskatchewan. Bivariate correlate and linear regression analyses were conducted using SPSS software technology to measure the association between day length in minutes and MMSE score $(n=154)$. Day length, mean temperature and MMSE score were the variables included in the multiple linear regression.

\section{Results}

Our data set was comprised of 154 RRMC patients. The most common diagnosis was Alzheimer's disease, followed by mild cognitive impairment (See Table 1). Mean day length was 739.55 minutes, which is equivalent to 12.5 hours; the range spanned 417 to 1046 minutes, or 7 to 17.5 hours. Mean daily temperatures ranged from $-25.2^{\circ} \mathrm{C}$ to $+25.0^{\circ} \mathrm{C}$, with an average mean daily temperature of $2.09^{\circ} \mathrm{C}$. Saskatchewan weather is characterized by extremes, and these temperatures appear reflective of the typical yearly climate pattern.

We found there to be no significant correlation between MMSE score and day length $(p=0.477)$. There was also no significant correlation between MMSE score and mean temperature $(p=0.554)$. The statistical analysis was repeated on patients with scores less than the median score, 22 (SD \pm 6.1 ; $n=72$ ), in order to focus our analysis on patients with more severe dementia. Again, we found there was no significant correlation between MMSE score and day length $(p=0.642)$ or mean temperature $(p=0.512)$. We carried out multiple linear regression with day length and temperature in the model. We did not find any significant relationship between MMSE score, day length and temperature (See Table 2).

\section{Discussion}

Our statistical analysis of the effect of day length and temperature on MMSE scores of RRMC patients strongly indicated that there was no significant association. However, with the high prevalence of visual impairments in older individuals, it is possible that some patients involved in our study may have been less susceptible to the effects of natural light. Use of artificial light may have increased the amount of daily illumination patients were subject to; especially during the winter months or in northern communities where day length would be particularly short, artificial light may have mitigated any effect of shortened day length. This study does not assess the amount of time participants spent outdoors directly exposed to natural sunlight.

A 2007 study found that high-intensity ambient light in public areas of long-term care facilities increased night-time sleep in dementia patients, with increases most prominent in those with severe dementia ${ }^{7}$. We had postulated that the effects of day length would similarly be more robust in patients with MMSE scores less than 22; however, no correlation was found. Because the RRMC aims to have early contact and involvement with dementia patients ${ }^{11}$, it is possible that at the six week follow-up appointment none of our participant's dementia was at a severity susceptible to light exposure.

To what extent light and temperature impact cognitive performance, in both dementia patients and the general population, is debatable ${ }^{6}$. Further research is needed to determine if natural light exposure is a useful treatment in improving cognitive performance and modulating circadian rhythm disorders.

\section{STATISTICAL ANALYSIS CONDUCTION}

Catherine Lacny, College of Medicine, University of Saskatchewan. 


\section{STUDY FUNDING}

Supported by College of Medicine, University of Saskatchewan.

\section{REFERENCES}

1. Dumont M, Beaulieu C. Light exposure in the natural environment: relevance to mood and sleep disorders. Sleep Med. 2007;8: 557-65.

2. Kent ST, McMclures LA, Crosson WL, Arnett DK, Wadley VG, Sathiakumar N. Effect of sunlight exposure on cognitive function among depressed and non-depressed participants: a REGARDS cross-sectional study. Environ Health. 2009;8(34).

3. Sullivan B, Payne TW. A comparison of seasonal and nonseasonal depression. Am J Psychiat. 2007;164:1663-7.

4. Bachman D, Rabins P. "Sundowning" and other temporally associated agitation states in dementia patients. Annu Rev Med. 2006;57:499-511.

5. Volicer L, Harper DG, Manning BC, Goldstein R, Satlin A. Sundowning and circadian rhythms in Alzheimer's Disease. Am J Psychiatry. 2001;158:704-11.
6. Forbes D, Culum I, Lischka AR, et al. Light therapy for managing cognitive, sleep, functional, behavioural, or psychiatric disturbances in dementia. Cochrane DB Syst Rev. 2009;4.

7. Sloane PD, Williams CS, Mitchell CM, et al. High-intensity environmental light in dementia: effect on sleep and activity. $\mathbf{J}$ Am Geriatr Soc. 2007;55:1524-33.

8. Morgan DG, Crossley M, Kirk A, et al. Improving access to dementia care: development and evaluation of a rural and remote memory clinic. Aging Ment Health. 2009;13(1):17-30.

9. Folstein MF, Folstein SE, McHugh PR. Mini-mental state: a practical method for grading the cognitive state of patients for the clinician. J Psychiatr Res. 1975; Nov12(3):189-98.

10. McEachern W, Kirk A, Morgan DG, Crossley M, Henry C. Reliability of the MMSE administered in-person and by telehealth. Can J Neuro Sci. 2008;35:643-6.

11. Morgan DG, Crossley M, Kirk A, et al. Evaluation of telehealth for preclinic assessment and follow-up in an interprofessional rural and remote memory clinic. J App Gerontol Epub 2010 Apr7. 